\title{
Lobectomy in patients with differentiated thyroid cancer: indications and follow-up
}

\author{
Jae Hyun Park and Jong Ho Yoon \\ Department of Surgery, Wonju Severance Christian Hospital, Yonsei University Wonju College of Medicine, Wonju, South Korea \\ Correspondence should be addressed to J H Yoon: gsyoon@yonsei.ac.kr
}

\begin{abstract}
The extent of thyroid surgery for patients with low- and intermediate-risk differentiated thyroid carcinoma (DTC), with a primary tumour $<4 \mathrm{~cm}$ and no extrathyroidal extension (ETE) or lymph node (LN) metastases, has shifted in a more conservative direction. However, clinicopathological risk factors, including microscopic ETE, aggressive histology, vascular invasion in papillary thyroid carcinoma (PTC) and intermediate volume of LN metastases, can only be identified after completing thyroid lobectomy. It is controversial whether patients with these risk factors should immediately undergo complete thyroidectomy and/or radioactive iodine remnant ablation or should be monitored without further treatments. Data are conflicting about the prognostic impact of these risk factors on clinical DTC outcomes. Notably, the recurrence rate in patients who underwent thyroid lobectomy is low and the few recurrences that develop during longterm follow-up can readily be detected by neck ultrasonography and treated by salvage surgery with no impact on survival. These findings suggest that a more conservative approach may be a preferred management strategy over immediate completion surgery, despite a slightly higher risk of structural recurrence. Regarding follow-up of postlobectomy DTC patients, it is reasonable that an initial risk stratification system based on clinicohistological findings be used to guide the short-term follow-up prior to evaluating the response to initial therapy and that the dynamic risk stratification system based on the response to initial therapy be used to guide long-term follow-up.
\end{abstract}

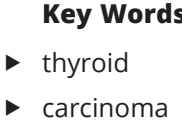

\section{Introduction}

Surgical treatment for a differentiated thyroid carcinoma (DTC) derived from follicular cells is a starting point of a multifaceted treatment approach. Even though DTC is generally non-aggressive and has good prognosis, choosing the extent of thyroid surgery for DTC remains controversial. The 2009 American Thyroid Association (ATA) guidelines for patients with DTC recommended total thyroidectomy as the initial surgical option for nearly all DTCs $>1 \mathrm{~cm}$ regardless of other risk factors, based on retrospective data suggesting benefits to survival, recurrence rate, routine use of radioactive iodine (RAI) remnant ablation and detection of recurrent disease using thyroglobulin (Tg) level (Cooper et al. 2009). However, recent large-scale studies found no significant survival difference between total thyroidectomy and thyroid lobectomy when adjusting for variables related to mortality risk or disease complexity and severity, besides tumour size (Nixon et al. 2012, Matsuzu et al. 2014). Recent data also show very similar clinical outcomes for thyroid lobectomy and total thyroidectomy, and the extent of initial thyroid surgery has little impact on disease-specific survival in properly selected low-to-intermediate-risk patients 
whose tumours are unifocal tumours $<4 \mathrm{~cm}$ and have no evidence of extrathyroidal extension (ETE) or lymph node (LN) metastases (Nixon et al. 2012, Matsuzu et al. 2014). Furthermore, the indication of RAI remnant ablation, a major reason for preferring total thyroidectomy, is becoming more selective in low-to-intermediate-risk DTC patients, and neck ultrasonography and serial serum $\mathrm{Tg}$ measurements are more preferred as follow-up tools than whole-body RAI scans requiring total thyroidectomy, even in patients treated without RAI remnant ablation (Haugen et al. 2016). These changes in management strategies for DTC patients, especially in low-to-intermediate-risk cases, may lower the need for total thyroidectomy and lead to revised guidelines. Therefore, changing paradigms require reassessment of the use of thyroid lobectomy.

\section{Current indications for thyroid lobectomy and completion thyroidectomy of DTC}

The 2015 ATA guidelines (Haugen et al. 2016) recommend thyroid lobectomy as the initial procedure for patients with DTC $\leq 1 \mathrm{~cm}$ (if surgery is chosen, instead of active surveillance), no ETE, no clinical LN metastasis, no prior history of head and neck irradiation and no familial history of thyroid carcinoma. Initial thyroid lobectomy is also recommended for patients with DTC $>1 \mathrm{~cm}$ and $\leq 4 \mathrm{~cm}$ (without ETE and clinical evidence of LN metastasis), low-risk PTC and follicular thyroid carcinoma (FTC). The 2015 ATA initial risk stratification system is shown in Table 1. In contrast, completion thyroidectomy is recommended for patients for whom total or near-total thyroidectomy would have been recommended if the diagnosis had been available before the initial surgery.

The National Comprehensive Cancer Network (NCCN) guidelines (Haddad et al. 2016) recommend that thyroid lobectomy can be an initial surgery for patients with DTC $\leq 4 \mathrm{~cm}$ without prior history of radiation exposure, distant metastasis, cervical LN metastasis or ETE upon preoperative or intraoperative evaluation. Completion thyroidectomy is recommended if the PTCs are $>4 \mathrm{~cm}$ and show positive resection margins, gross ETE, macroscopic multifocal disease, macroscopic LN metastasis ( $\geq 3-5$ involved LNs or $>0.5 \mathrm{~cm}$ for largest dimension) or postoperative vascular invasion. It is also recommended for invasive FTCs or Hürthle cell carcinomas with extensive vascular invasion ( $>4$ foci) and for a part of minimally invasive FTCs or Hürthle cell carcinomas (defined as a well-defined tumour

Table 1 The 2015 revised American Thyroid Association initial risk stratification system.

\begin{tabular}{|c|c|c|c|}
\hline & Low & Intermediate & High \\
\hline Tumour & $\begin{array}{l}\text { No tumour invasion of locoregional } \\
\text { tissues or structures } \\
\text { Not aggressive histology (e.g., tall cell, } \\
\text { hobnail variant, columnar cell } \\
\text { carcinoma) } \\
\text { No vascular invasion } \\
\text { Intrathyroidal, encapsulated follicular } \\
\text { variant of PTC } \\
\text { Intrathyroidal, well differentiated FTC } \\
\text { with capsular invasion and no or } \\
\text { minimal (<4 foci) vascular invasion } \\
\text { Intrathyroidal, PTMC, unifocal or } \\
\text { multifocal, including BRAFV600E } \\
\text { mutated (if known) }\end{array}$ & $\begin{array}{l}\text { Microscopic invasion of tumour } \\
\text { into the perithyroidal soft tissues } \\
\text { Aggressive histology (e.g., tall cell, } \\
\text { hobnail variant, columnar cell } \\
\text { carcinoma) } \\
\text { PTC with vascular invasion } \\
\text { Multifocal PTMC with ETE and } \\
\text { BRAFV600E mutated (if known) }\end{array}$ & $\begin{array}{l}\text { Macroscopic invasion of tumour } \\
\text { into the perithyroidal soft } \\
\text { tissues (gross ETE) } \\
\text { FTC with extensive vascular } \\
\text { invasion ( }>4 \text { foci of vascular } \\
\text { invasion) }\end{array}$ \\
\hline Node & $\begin{array}{l}\text { Clinical N0 } \\
\leq 5 \text { pathologic } \mathrm{N} 1(<0.2 \mathrm{~cm} \text { in largest } \\
\text { dimension) }\end{array}$ & $\begin{array}{l}\text { Clinical N1 } \\
>5 \text { pathologic N1 with all involved } \\
\text { lymph nodes }<3 \mathrm{~cm} \text { in largest } \\
\text { dimension }\end{array}$ & $\begin{array}{l}\text { Pathologic } \mathrm{N} 1 \text { with any } \\
\text { metastatic lymph node } \geq 3 \mathrm{~cm} \\
\text { in largest dimension }\end{array}$ \\
\hline $\begin{array}{l}\text { Distant } \\
\text { metastasis }\end{array}$ & No distant metastases & No distant metastases & Distant metastases \\
\hline Others & $\begin{array}{l}\text { All macroscopic tumour has been } \\
\text { resected } \\
\text { No RAl-avid metastatic foci outside the } \\
\text { thyroid bed on the first post-treatment } \\
\text { whole-body RAl scan }\end{array}$ & $\begin{array}{l}\text { RAl-avid metastatic foci in the neck } \\
\text { on the first post-treatment } \\
\text { whole-body RAI scan }\end{array}$ & $\begin{array}{l}\text { Incomplete tumour resection } \\
\text { Postoperative serum Tg } \\
\text { suggestive of distant } \\
\text { metastases }\end{array}$ \\
\hline
\end{tabular}

ETE, extrathyroidal extension; FTC, follicular thyroid carcinoma; PTC, papillary thyroid carcinoma; PTMC, papillary thyroid microcarcinoma; RAI, radioactive iodine; $\mathrm{Tg}$, thyroglobulin.

(c) 2019 Society for Endocrinology Published by Bioscientifica Ltd. Printed in Great Britain 
with microscopic capsular and/or 1-4 foci of vascular invasion) on final histopathologic examination.

The 2014 British Thyroid Association (BTA) guidelines (Perros et al. 2014) recommended total thyroidectomy for patients with PTCs $>4 \mathrm{~cm}$ or PTCs with multifocal disease, bilateral disease, ETE (pathologic T3 and T4), familial disease, clinically or radiologically involved LNs or distant metastases. Furthermore, it stated that the evidence is unclear for an advantage of total thyroidectomy over hemi-thyroidectomy in patients with unifocal PTCs $1-4 \mathrm{~cm}$ in diameter and no other adverse factors such as age $>45$ years, ETE, familial disease, clinical or radiological evidence of LN or distant metastasis and angioinvasion. Therefore, these cases require personalised decision making and consideration of risk factors such as tumour $>2 \mathrm{~cm}$, positive positron emission tomography, poorly differentiated component or radiation-induced cancer. Completion thyroidectomy is recommended for Hürthle cell carcinomas $>1 \mathrm{~cm}$ and for FTCs $>4 \mathrm{~cm}$ or those with adverse risk factors, such as age $>45$ years, wide invasiveness, LN or distant metastasis and angioinvasion.

Various preoperative and postoperative clinicopathologic features are used to predict mortality risk and to stratify the risk of structural recurrence after initial surgery. Based on each clinicopathologic variable's impact on survival and structural recurrence, they are also preoperatively used to decide the extent of initial surgical treatment for DTC, as for the international guidelines above. In predicting DTC mortality, the American Joint Committee on Cancer/Union for International Cancer Control (AJCC/UICC) Tumour Node Metastasis (TNM) staging system and the Metastasis Age Completeness of resection Invasion Size (MACIS) system provide the highest proportion of variance explained (PVE; defined as a statistical measure of how well a staging system predicts the outcome of interest) (Voutilainen et al. 2003, Lo et al. 2005, Yildirim 2005). Unfortunately, however, none of these staging systems can account for more than 5-30\% (corresponding to PVE values of 0.05-0.30) of the uncertainty associated with eventual death from DTC (Voutilainen et al. 2003, Lo et al. 2005, Yildirim 2005). This inadequacy of these staging systems in predicting DTC mortality risk may be due to a lack of integration with clinicopathologic risk factors besides age, primary tumour size, ETE, location of LN metastasis and distant metastasis. Furthermore, the AJCC/TNM staging system does not adequately predict DTC recurrence (Tuttle et al. 2010).

Unlike these staging systems that predict DTC mortality, the 2015 ATA initial risk stratification system predicts the risk of structural recurrence during follow-up, based on histopathologic findings obtained immediately after initial DTC surgery (Table 1). The 2015 ATA initial risk estimates incorporate detailed variables, including DTC variants, mutational status, extent of LN involvement and degree of vascular invasion in FTC. Although the comparative benefit between the 2015 ATA initial risk estimates and 2009 ATA initial risk stratification system are not established, the latter had PVE values of 19-34\% (Tuttle et al. 2010, Castagna et al. 2011). Moreover, a retrospective evaluation of the 2009 ATA initial risk stratification system suggested that it may be applied even in patients treated without RAI remnant ablation as well as in patients who underwent total thyroidectomy and subsequent RAI remnant ablation (Vaisman et al. 2011, Durante et al. 2012). The variables used in this risk stratification system not only guide follow-up management, but also aid in deciding the extent of surgery for the initial surgical treatment. However, because the recurrence risk of each clinicopathological feature within the same risk categories (low, intermediate and high) varies and risk factors can be closely interrelated, the risk factors for structural recurrence should be analysed with appropriate statistical methods to adjust for interference between variables.

Notably, risk factors within the same risk categories can be subdivided into two subgroups, according to preoperative or postoperative identification. Unlike high-risk factors that are preoperatively identified (except for extensive vascular invasion $>4$ foci in FTC and postoperative serum $\mathrm{Tg}$ level suggestive of distant metastases) and usually result in total thyroidectomy, the clinicopathologic features for the intermediate-risk category cannot be preoperatively identified. Because intermediate-risk factors identified after initial surgical treatment may be cause for completion thyroidectomy, the impact of intermediate-risk factors on structural recurrence must be reviewed and reassessed.

\section{Impact of clinicopathologic features on survival or structural recurrence}

\section{Primary tumour size}

The risk of structural recurrence is $1-2 \%$ in unifocal intrathyroidal papillary thyroid microcarcinoma (PTMC), 4-6\% in multifocal intrathyroidal PTMC, $5-6 \%$ in intrathyroidal PTC $2-4 \mathrm{~cm}$ and $8-10 \%$ in intrathyroidal PTC $>4 \mathrm{~cm}$ (Roti et al. 2008, Ito et al. 2012). (c) 2019 Society for Endocrinology Published by Bioscientifica Ltd. Printed in Great Britain 
A retrospective study of 2345 patients with $1-4 \mathrm{~cm}$ PTC found no significant difference in disease-free survival (DFS) between a total thyroidectomy group and a thyroid lobectomy group after 1:1 propensity score matching by age, sex, primary tumour size, ETE, multifocality and cervical LN metastasis (381 patients in each group, median follow-up duration of 9.8 years) (hazard ratio $(\mathrm{HR})=1.35$ (confidence interval (CI) 0.40-1.36), $P=0.33$ ) (Song et al. 2019). Moreover, when stratified by primary tumour size, DFS did not differ between $1-2 \mathrm{~cm}$ tumours and $2-4 \mathrm{~cm}$ tumours ( $\mathrm{HR}=1.57$ (CI 0.75-3.25), $P=0.228$; $\mathrm{HR}=0.93$ (CI 0.30-2.89), $P=0.902$, respectively) (Song et al. 2019). Multivariate analysis found that surgical extent had no independent role in structural recurrence (HR=1.43 (CI 0.72-2.83), $P=0.306$ ), emphasising that primary tumour size should not be an absolute indication for total thyroidectomy (Song et al. 2019). Another study analysed 2323 DTC patients with T1-T3 classifications and found that tumour size of $>4 \mathrm{~cm}$ independently predicted DFS, locoregional failure and distant metastatic failure (Tam et al. 2018). In contrast, a large-scale retrospective study using the National Cancer Data Base evaluated 33,816 PTCs with $1.0-3.9 \mathrm{~cm}$ tumours and clinically negative LNs $(30,981$ receiving total thyroidectomy and 2835 undergoing thyroid lobectomy) (Rajjoub et al. 2018). In this study, adjusted analyses showed that total thyroidectomy for classic PTCs was associated with improved survival for $2.0-3.9 \mathrm{~cm}$ tumours $(P=0.03)$, but not for $1.0-1.9 \mathrm{~cm}$ tumours $(P=0.16)$. However, thyroid lobectomy and total thyroidectomy for follicular-variant PTCs had equivalent survival for $1.0-1.9 \mathrm{~cm} \quad(P=0.45)$ and $2.0-3.9 \mathrm{~cm}(P=0.88)$ tumours (Rajjoub et al. 2018). Lee et al. retrospectively analysed 762 patients with classic PTC of $1-4 \mathrm{~cm}$ who underwent initial surgery (693 total thyroidectomy and 69 thyroid lobectomy, median follow-up duration of 124 months). Their multivariate analysis showed that primary tumour size $>1.95 \mathrm{~cm}$ was an independent risk factor for structural recurrence, unlike the extent of thyroid surgery (Lee et al. 2018). Similarly, a retrospective multivariable analysis of 3174 DTC patients (2921 total thyroidectomy and 253 thyroid lobectomy, median follow-up duration of 12.4 years) showed that primary tumour sizes of $2.1-4.0 \mathrm{~cm}$ and $>4.0 \mathrm{~cm}$ were both independent risk factors for disease-specific survival (DSS) $(\mathrm{HR}=2.44$ (95\% CI 1.45-4.11), $P=0.001$ and HR 7.40 (95\% CI 4.02-13.63), $P<0.001$, respectively) and DFS $(\mathrm{HR}=1.97(95 \%$ CI $1.52-2.55), P<0.001$ and $\mathrm{HR}=2.91$ (95\% CI 1.92-4.42), $P<0.001$, respectively), with a primary tumour size reference of $\leq 2.0 \mathrm{~cm}$ (Park et al. 2018b).

\section{Extrathyroidal extension}

Based on the 7th AJCC/UICC TNM staging system (TNM-7), it is important to differentiate the clinical significance of minimal ETE (pathologic T3 classification, including microscopic ETE) from extensive ETE (pathologic T4 classification). The risk of structural recurrence associated with minimal ETE ranges from 3 to $9 \%$, whereas that related to extensive ETE ranges from 23 to $40 \%$ (Lombardi et al. 2010, Radowsky et al. 2014). A retrospective analysis of $1-4 \mathrm{~cm}$ classic PTC patients found that the presence of extensive ETE was an independent risk factor for structural recurrence $(\mathrm{HR}=6.84$ (95\% CI 2.20-21.33), $P<0.001$, with a reference of no ETE), whereas minimal ETE was not (Lee et al. 2018). Another study also found that minimal ETE was not an independent risk factor for tumour recurrence in T1-T3 DTC patients (Tam et al. 2018). In addition, Park et al. evaluated the prognostic significance of gross ETE invading only strap muscles in 3174 DTC patients, revealing that the 10-year recurrencefree survival rate for patients with gross ETE invading only strap muscles $(89.2 \%)$ was shorter than that for patients with no ETE $(93.7 \%, P=0.017)$, but similar to that of patients with microscopic ETE (90.3\%) (Park et al. 2018b). However, multivariable analysis showed that although extensive ETE independently predicted recurrence-free survival ( $\mathrm{HR}=1.60$ (95\% CI 1.05-2.43), $P=0.027$ ), gross ETE invading only strap muscles did not $(\mathrm{HR}=1.09$ (95\% CI 0.71-1.69), $P=0.685$ ) (Park et al. 2018b).

The recent 8th AJCC TNM staging system (TNM-8) for DTC has removed microscopic ETE from the definition of T3 disease. These changes reflect evidence that the status of microscopic ETE as an independent prognostic factor in PTC has been increasingly questioned.

\section{LN involvement}

With respect to LN metastases, the risk of structural recurrence varies from $4 \%$ in involved LNs $\leq 5$, to $5 \%$ when all involved LNs are $<0.2 \mathrm{~cm}$, to $19 \%$ in involved LNs $>5$, to $21 \%$ in involved LNs $>10$, to $22 \%$ in clinically evident macroscopic LN metastases and $27-32 \%$ when any metastatic $\mathrm{LN}$ is $>3 \mathrm{~cm}$ (Randolph et al. 2012, Lee et al. 2014). Extranodal extension of the tumour through the metastatic LN capsule is also associated with an increased risk of structural recurrent disease (Leboulleux et al. 2005).

Unfortunately, these risk estimates have been applied equally to N1a and N1b disease because there were insufficient data to determine each LN-related risk factor based on location within the neck. Furthermore, because 
many studies evaluating LN-related risk factors of PTC included patients with both N1a and N1b classifications, the LN-related risk factors from PTCs with N1b classification might hide small but significant LN-related factors in N1a-classified patients.

Another retrospective analysis of 324 classical PTC patients classified with pathologic N1b evaluated risk factors for structural recurrence (Lee et al. 2016). This study separately assessed the LN-related variables (maximal diameter of metastatic LN foci, number of metastatic and retrieved LNs, metastatic LN ratio and ENE) based on the LN location (central vs lateral compartment) and found that maximal diameter of metastatic LN foci $>2.0 \mathrm{~cm}$ $(\mathrm{HR}=1.15$ (95\% CI 1.06-1.25), $P=0.033)$ and central metastatic $\mathrm{LN}$ ratio $>0.42$ ( $\mathrm{HR}=3.35$ (95\% CI 1.65-6.79), $P<0.001)$ were independent risk factors for locoregional recurrence. Additionally, the presence of ENE (HR $=12.71$ (95\% CI 1.64-98.25), $P=0.015$ ) was an independent risk factor for distant metastasis in multivariate analyses (Lee et al. 2016).

Although the traditional cut-off of $<0.2 \mathrm{~cm}$ for LN micrometastasis is commonly accepted, this definition was not derived from PTCs but from breast cancer and other solid tumours. Therefore, an appropriate cut-off of LN micrometastasis must be determined for PTC patients. Recently, retrospective multivariate analyses of 398 classic PTC patients who received total thyroidectomy with CCND and a confirmed pathologic N1a classification found that a maximal diameter of $>3.5 \mathrm{~mm}$ for metastatic LN foci (HR $=3.76$ (95\% CI 2.27$6.24), P<0.001)$ and $\geq 4$ involved $\mathrm{LNs}(\mathrm{HR}=3.01$ (95\% CI $1.82-4.92), P<0.001)$ were independent risk factors for structural recurrence, and patients with each risk factor had significantly poorer DFS rates than their counterparts without these risk factors (Lee et al. 2019). These results are consistent with the NCCN guidelines suggesting that macroscopic LN metastases ( $\geq 3-5$ involved LNs or $>0.5 \mathrm{~cm}$ in largest dimension) adversely affect prognosis, whereas LN micrometastases $(<3-5$ involved LNs and $\leq 0.5 \mathrm{~cm}$ in largest dimension) are associated with low structural recurrence risk (Haddad et al. 2016).

The revised TNM-8 entails important changes from the seventh edition for patients with DTC. One notable change is that TNM-8 categorises pathologic N1a and N1b classifications together into pathologic N1 classification; thus, N1b classification is no longer a variable for determining the final TNM stage, even though it may be debatable. In addition, age criterion for determining TNM stage is changed from 45 to 55 years. Based on these changes in the TNM-8, large number of patients with differentiated thyroid cancer would be down-staged as compared with being staged by the TNM-7. In our opinion, because the TNM-8 staging system is newly adopted since 2018, further validation may be needed based on large scale of patients with long follow-up period.

\section{Multifocality}

Recently, a large-scale multicentre study investigated the role of tumour multifocality in clinical PTC outcomes in 2638 patients with a median follow-up time of 58 months (range: 26-107 months) at 11 medical centres in six countries, and used Surveillance, Epidemiology and End Results (SEER) data for validation. Multifocality was not a significant risk factor for structural recurrence (HR $=1.13$ (95\% CI 0.93-1.37), $P=0.233$ ) in multivariate adjustment. Similarly, there was no association between multifocality and mortality in PTC variants: classical PTC, follicularvariant PTC, tall-cell PTC and PTMC (Wang et al. 2017). These results were reproduced in 89,680 patients with PTC in the SEER database. The findings emphasise that tumour multifocality has no independent risk prognostic value for clinical PTC outcomes, and its indiscriminate use as an independent risk factor should be avoided to prevent patient overtreatment. Other multivariate analyses also found that multifocality was not an independent risk factor of structural recurrence (Leboulleux et al. 2005).

\section{Histological variants}

Tall-cell variant (TCV), columnar cell variant (CCV), hobnail variant and solid variant of PTC are aggressive histologic subtypes (Haugen et al. 2016).

The TCV of PTC is the most common variant (incidence of 1-19.0\%) and is more prevalent in males and older patients. Compared to classic PTC, TVC is associated with a higher frequency of aggressive histopathologic features at diagnosis, including large primary tumour size, multifocality, ETE, LN metastases and distant metastases (Nath \& Erickson 2018). Furthermore, several studies suggest that the tall-cell histology independently affects structural recurrence and survival. In a multivariate analyses of 183 PTCs, including 19 TCVs, tall-cell histology was an independent risk factor for structural recurrence (Terry et al. 1994). A SEER-based study of 278 TCVs of PTC and 2522 classic PTCs found that 5-year DSS of TCVs was worse than that of classic PTCs ( 81.9 vs $97.8 \%, P<0.001$ ) (Morris et al. 2010). Another SEER-based study also found that TCVs of PTC had shorter 5-year overall survival (80.6 vs $93.5 \%, P<0.001$ ) after adjusting for other factors 
(Kazaure et al. 2012). However, other contradicting multivariate analyses suggest that tall-cell histology is not an independent risk factor for structural recurrence and mortality (Michels et al. 2007).

The CCV of PTC can also be aggressive. Even though there are few reports, the aggressive CCVs of PTC were associated with male gender, old age, large tumour size, ETE, diffuse infiltration, laryngotracheal invasion, cervical LN metastases, distant metastases and high AJCC/UICC TNM stage. Furthermore, the DSS of patients with aggressive disease was shorter than that of patients with indolent disease (Nath \& Erickson 2018).

The solid/trabecular variant of PTC accounted for approximately $37 \%$ of PTC associated with the Chernobyl nuclear disaster. This variant is more common in young patients and those with a history of ionising radiation exposure and has a higher frequency of distant metastases (usually to the lung) and less favourable prognosis. The mortality rate for this tumour in adults has been reported to be up to $10 \%$ (Nath \& Erickson 2018).

The recently described hobnail variant of PTC is associated with aggressive features, including high AJCC/UICC TNM stage at presentation (stage III or IV in $62.5 \%$ ), old age, vascular invasion (41.7\%), LN metastases at presentation (up to $75 \%$ ) and distant metastases (up to 43.5\%) (Asioli et al. 2013, Lubitz et al. 2014). Furthermore, the hobnail variant of PTC is often associated with other aggressive histologic types of thyroid carcinoma and has significant mortality (33.3\%) (Asioli et al. 2013, Lubitz et al. 2014).

The 2015 ATA guidelines histologically defined TCV, CCV and hobnail variants as aggressive. However, the evidence associating these aggressive histologic subtypes of PTC with unfavourable outcomes is limited, because most previous studies had small numbers of patients due to the rarity of the subtypes, except for TCV of PTC. Furthermore, no clinical studies compare prognoses of $\mathrm{CCV}$ and hobnail variant with that of classic PTC. More importantly, most previous studies did not adjust for major clinicopathologic factors affecting clinical outcomes.

These limitations lead to questioning whether each aggressive histologic subtype has an impact on clinical outcomes compared to classic PTC, even when other clinicopathologic factors are identical. Recently, a retrospective study compared DFS in 144 patients with three aggressive variants of PTC and 763 patients with classic PTC, after propensity score matching by age, sex, primary tumour size, LN metastasis and ETE. This study found that the group of aggressive PTC variants had significantly lower DFS than the matched classic PTC group $(\mathrm{HR}=2.16$ (95\% CI 1.12-4.16), $P=0.018$ ) (Song et al. 2018). However, when TCVs and CCVs were evaluated separately, there was no significant differences in DFS and dynamic risk stratification (DRS) between patients with TCV $(n=121)$ and matched classic PTC, whereas the CCV group $(n=18)$ had significantly poorer DFS than the matched classic PTC group (HR=12.19 (95\% CI 2.11-70.33), $P=0.005$ ) (Song et al. 2018). Furthermore, $\mathrm{CCV}$ was an independent risk factor for structural recurrence in multivariate analysis $(\mathrm{HR}=4.28$ (95\% CI 1.66-11.00) $P=0.001$ ), suggesting the use of individualised therapeutic approaches for each type of aggressive PTC variant (Song et al. 2018).

\section{Vascular invasion}

Minimally invasive FTCs (MIFTCs) with either only capsular invasion or only minor vascular invasion (1-3 foci of vascular invasion) usually have an excellent prognosis with low recurrence rates (0-3\%; Goldstein et al. 2000, O'Neill et al. 2011 or 0-5\%; Lang et al. 1986, Huang et al. 2011) and stratified as low risk in the 2015 ATA guidelines. In contrast, patients with MIFTC who have extensive vascular invasion ( $\geq 4$ foci of vascular invasion) are considered to be high risk for structural recurrence because there is high risk of developing newly identified distant metastases (Collini et al. 2004, Huang et al. 2011, O'Neill et al. 2011, Sugino et al. 2011). In most previously published studies, age $\geq 45$ years, primary tumour size $\geq 4 \mathrm{~cm}$, presence of vascular invasion, extensive vascular invasion ( $\geq 4$ foci), LN metastases and distant metastases at the initial diagnosis are prognostic for distant metastasisfree survival (DMFS) and DSS rates in MIFTC patients (Collini et al. 2004, Lo et al. 2005, O'Neill et al. 2011, Sugino et al. 2011). Therefore, these risk factors are widely used as criteria to recommend completion thyroidectomy to patients diagnosed with MIFTC after diagnostic thyroid lobectomy.

A previous retrospective multivariate analysis of 166 MIFTC patients with a median follow-up period of 103.5 months found that vascular invasion $(\mathrm{HR}=29.06$ (95\% CI 3.06-209.08), $P=0.015$ ) and extensive vascular invasion ( $\geq 4$ foci) ( $\mathrm{HR}=40.57$ (95\% CI 2.09-789.13), $P=0.014)$ were the only independent risk factors for distant metastasis (Lee et al. 2017). However, surgical extent ( $\mathrm{HR}=1.57$ (95\% CI 0.29-8.47), $P=0.598)$ and RAI remnant ablation or lack thereof $(\mathrm{HR}=2.73$ (95\% CI 0.44-17.04), $P=0.284$ ) were not independent risk factors for distant metastasis, demonstrating that further (c) 2019 Society for Endocrinology Published by Bioscientifica Ltd. Printed in Great Britain 
treatment after initial thyroid lobectomy did not prevent distant metastasis at follow-up (Lee et al. 2017).

In PTC, the prognostic impact of vascular invasion is controversial. A multivariate analysis of 412 PTC patients matched for age, gender, histologic variants and TNM stage found that vascular invasion $(\mathrm{HR}=3.63$ (95\% CI 1.47-8.94), $P=0.005$ ) was an independent risk factor for distant metastasis, and patients with vascular invasion had significantly shorter DMFS $(P<0.001)$ (Cao et al. 2016). In contrast, another multivariate analysis of 698 DTC patients showed that vascular invasion was significantly associated with a primary tumour size of $>4.0 \mathrm{~cm}$, ETE, distant metastasis and RAI treatment, but was not an independent predictor of DMFS (Wreesmann et al. 2015).

\section{B-type Raf kinase (BRAF V600E) mutation status}

To resolve conflicts from various single-centre studies, several meta-analyses and multicentre studies assessed the prognostic significance of the BRAFV600E mutation. In a systematic review and meta-analysis of 2470 PTC patients from nine different countries, risk ratios in $B R A F$ mutation-positive patients were 1.93 (95\% CI 1.61-2.32, $P<0.00001)$ for structural recurrence, 1.32 (95\% CI 1.20-1.45, $P<0.00001)$ for LN metastasis, 1.71 (95\% CI 1.50-1.94, $P<0.00001)$ for ETE, 0.95 (95\% CI $0.63-1.44, P=0.82)$ for distant metastasis and $1.70(95 \% \mathrm{CI}$ $1.45-1.99, P<0.00001$ ) for advanced stage III/IV (Tufano et al. 2012). Another meta-analysis of 2247 PTMC patients revealed that patients with a $B R A F V 600 \mathrm{E}$ mutation had a higher likelihood of structural recurrence (odds ratio (OR) 2.09 (95\% CI 1.31-3.33), $P=0.002$ ) (Chen et al. 2016). However, because the BRAFV600E mutation is tightly linked to conventional risk factors for recurrent disease, it is difficult to determine the proportion of risk attributable to the BRAF mutation versus other clinicopathologic features. Several studies (Xing et al. 2005, Elisei et al. 2012), but not all (Kim et al. 2006, Fernandez et al. 2013), demonstrated that BRAFV600E mutation is an independent predictor for risk of structural recurrence in multivariate analysis. A large multicentre pooled-data evaluation of 2099 patients found that the BRAFV600E mutation was significantly associated with the risk of structural recurrence in PTCs (20.9 vs $11.6 \%$, HR 1.38 (95\% CI 1.07-1.80), $P<0.001$ after adjustment for age, sex, primary tumour size, ETE, LN metastasis, multifocality, and PTC subtypes).
This significant association was also found in patients with stage I or II, PTMC and subtypes of PTC (classicor follicular-variant) (Xing et al. 2015). Another retrospective multicentre study of 1849 PTC patients from 13 centres in seven countries investigated the relationship between BRAFV600E mutation and PTCrelated mortality (Xing et al. 2013). The overall mortality for PTC cases in BRAFV600E-positive patients was $5.3 \%(45 / 845 ; 95 \% \mathrm{CI}, 3.9-7.1 \%)$ vs $1.1 \%$ (11/1004; 95\% CI, $0.5-2.0 \%)$ in mutation-negative patients with PTC after adjustment for age and sex (HR 2.66 (95\% CI 1.30-5.43), $P<0.001$ ) (Xing et al. 2013). However, when also adjusted for LN metastasis, ETE and distant metastasis, the association of BRAFV600E with mortality was no longer statistically significant (for all PTC: HR, 1.21 (95\% CI 0.53-2.76); for classic PTC: HR 1.51 (95\% CI 0.50-4.57)); however, BRAFV600E-positive patients had significantly poorer survival in each analysis (Xing et al. 2013).

Recent data also suggest that thyroid carcinoma is likely to be aggressive when a BRAF mutation is concurrent with other oncogenic mutations, including TERT promoter, PIK3CA or TP53 mutation (Ricarte-Filho et al. 2009, Xing et al. 2014). These types of combinations of mutations are expected to be more specific markers of unfavourable PTC outcomes (Haugen et al. 2016). Based on these data, it appears that the BRAF status alone is not sufficient to substantially contribute to risk stratification for most patients. Therefore, $B R A F$ mutational evaluation for initial postoperative risk stratification in DTC is not routinely recommended. The BRAFV600E mutational status can be most helpful for deciding initial surgical extent or postoperative management when it is presented with other concurrent clinicopathological risk factors for structural recurrence.

\section{Proposed indications for thyroid lobectomy for DTC}

Based on a review of theimpacts of various clinicopathologic features on structural recurrence or survival, we present proposed indications for thyroid lobectomy for DTC in Table 2. Variables classified into indications for thyroid lobectomy had profoundly conflicting data from previous studies or lacked evidence due to insufficient data. Thus, these classifications required larger scale multinational and multicentre study with longer follow-up periods.

The most confusing data were that regarding LN involvement. Most international guidelines do not 
Table 2 Proposed indications and contraindications of thyroid lobectomy for differentiated thyroid carcinoma.

Completion
thyroidectomy after
thyroid lobectomy
Primary tumour size

ETE

LN involvement

Multifocality

Histologic variants

Vascular invasion

\section{Absolute indications \\ Not recommended}

$\leq 1 \mathrm{~cm}$ (if patients choose surgery) and $>1 \mathrm{~cm}$ and $\leq 2 \mathrm{~cm}$ No

Clinical NO and number of metastatic LNs $<3$ (or 5) and maximal diameter of metastatic foci of LNs $\leq 0.35$ (or 0.5 ) $\mathrm{cm}$ and metastatic $\mathrm{LN}$ ratio $\leq 0.4$ Absent or present

Classic

In FTC, absent or $<4$ foci of vascular invasion In PTC, absent

BRAFV600E mutation Wild

Relative indications
$\begin{aligned} & \text { Personalised decision making regarding other } \\ & \text { concurrent clinicopathologic risk factors }\end{aligned}$
$>2 \mathrm{~cm}$ and $\leq 4 \mathrm{~cm}$
Minimal (microscopic or only invasion of strap
muscle)
Number of metastatic $L N \mathrm{Ns} \geq 3$ (or 5 ) or
maximal diameter of metastatic foci of LNs
$>0.35$ (or 0.5 ) cm and $\leq 2$ (or 3 ) cm or
metastatic LN ratio $>0.4$ (if compartment-
oriented LN dissection was performed)

Contraindications

Recommended

$>4 \mathrm{~cm}$

Extensive (T4)

Clinical N1 or maximal diameter of metastatic foci of LNs > 2 (or 3) cm

Tall cell, Columnar cell, Hobnail

In PTC, present

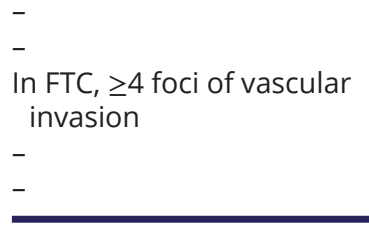

ETE, extrathyroidal extension; FTC, follicular thyroid carcinoma; LN, lymph node; PTC, papillary thyroid carcinoma.

recommend prophylactic central LN dissection without evidence of LN metastasis upon physical examination or preoperative imaging studies. Therefore, it is difficult to evaluate the significance of microscopic or low-volume LN metastasis based on a large patient cohort. Furthermore, the extent and skill of central LN dissection differ between institutions and surgeons. Therefore, the significance and general applicability of data for LN-related risk factors for structural recurrence and survival must be limited, because it was mostly based on single-centre studies.

As described earlier, the management strategies for DTC patients, especially low- to intermediate-risk patients, are undergoing change. The indications for RAI remnant ablation are shifting more selectively towards low-tointermediate-risk DTC patients, and follow-up tools are now shifting away from whole-body RAI scan and towards neck ultrasonography and serial serum Tg measurements, even in patients not treated with RAI remnant ablation. These changes decrease the use of total thyroidectomy in low-to-intermediate-risk DTC patients.

DTC patients treated with lobectomy (unilateral lobectomy and/or isthmusectomy) and no RAI have excellent outcomes (Durante et al. 2012, Vaisman et al. 2013, Matsuzu et al. 2014). Recurrence rates for ATA low-to-intermediate-risk patients selected for thyroid lobectomy were $4.1-5.7 \%$ in the thyroid remnant, $1-8.5 \%$ in regional LNs, $0-3.2 \%$ in distant metastatic sites and 0-2.0\% mortality (Durante et al. 2012, Vaisman et al. 2013, Matsuzu et al. 2014). Over a median follow-up period that

(c) 2019 Society for Endocrinology Published by Bioscientifica Ltd. Printed in Great Britain ranged from 5-10 years, structural recurrence was found in less than $1-2 \%$ of ATA low-risk patients and $8 \%$ of ATA intermediate-risk patients, who underwent thyroid surgery without RAI ablation as initial therapy (Vaisman et al. 2011, Durante et al. 2012).

The few recurrences that develop during long-term follow-up are readily detected by neck ultrasonography and treated without affecting survival, because salvage therapy is effective in the minority of patients that experience recurrence after thyroid lobectomy (Vaisman et al. 2011, Nixon et al. 2012, Matsuzu et al. 2014). Therefore, although some controversial clinicopathologic features may be found after thyroid lobectomy, a more conservative management approach might be a reasonable alternative to immediate completion surgery, despite the slightly higher risk of structural recurrence.

It has been well known that the surgical morbidity associated with thyroid surgery, including recurrent laryngeal nerve injury and hypoparathyroidism, is absolutely less in patients undergoing thyroid lobectomy than in those undergoing total thyroidectomy. In addition, institutional studies examining outcomes following thyroidectomy by high-volume surgeons have been published demonstrating overall safety. Sosa et al. found a strong association between higher surgeon volume and favourable patient outcomes, especially with regard to recurrent laryngeal nerve injury and wound complications (Sosa et al. 1998). In a recent study of patients undergoing thyroidectomy in the Health Care 
Utilization Project Nationwide Inpatient Sample (HCUPNIS), high-volume surgeons had the lowest complication rates for patients who underwent total thyroidectomy for cancer at 7.5\%; intermediate-volume surgeons had a rate of $13.4 \%$ and low-volume surgeons $18.9 \%(P<0.001)$ (Kandil et al. 2013). Therefore, it may be reasonable to consider sending patients with more extensive disease and concern for grossly invasive disease to a high-volume surgeon experienced in the management of advanced thyroid cancer.

\section{Short-term follow-up strategies of DTC patients undergoing thyroid lobectomy}

The intensity and frequency of short-term follow-up strategies for DTC patients treated solely with thyroid lobectomy are not well established, likely because most previous international guidelines recommended total thyroidectomy for nearly all PTCs $>1 \mathrm{~cm}$. Therefore, there are few data available for patients with PTCs who underwent thyroid lobectomy, especially those with PTCs measuring $1-4 \mathrm{~cm}$.

The 2014 BTA guidelines (Perros et al. 2014) suggest that patients who have not received RAI remnant ablation do not require TSH suppression so long as TSH levels are maintained in the low-normal range $(0.3-2.0 \mathrm{mU} / \mathrm{L})$. For patients who underwent thyroid lobectomy for a tumour $\leq 1 \mathrm{~cm}$ and have no other adverse factors as mentioned earlier, TSH suppression or long-term follow-up is not recommended. The exception is annual thyroid function testing, and replacement treatment with levothyroxine may be required in patients with overt hypothyroidism. Furthermore, these guidelines do not recommend TSH suppression even for thyroid lobectomy patients with lowrisk tumours (between $1-4 \mathrm{~cm}$ ), and instead recommend personalised decision making that considers additional risk factors $(>2 \mathrm{~cm}$, positron emission tomography positive, poorly differentiated component or radiationinduced cancer) to determine frequency and duration of follow-up. For low-risk patients with no evidence of disease, and only annual measurement of serum $\mathrm{Tg} / \mathrm{anti}-\mathrm{Tg}$ antibody and TSH is recommended.

The NCCN guidelines (Haddad et al. 2016) recommend measuring $\mathrm{Tg}$ and anti-Tg antibody 6-12 weeks after initial surgery and assessing trend patterns in thyroid lobectomy patients. Physical examination, TSH and $\mathrm{Tg} /$ anti-Tg antibody measurements are recommended 6 and 12 months after the initial operation, and annually thereafter if patients are disease free. Periodic neck ultrasound is recommended only for patients with reasonable suspicion of structural recurrence. TSH suppression therapy with levothyroxine is theoretically recommended to maintain low TSH levels, although data to allow for precise specification of the appropriate target TSH levels is lacking. In general, target TSH levels are either slightly below or slightly above the lower limit of the reference range for disease-free patients who are at low risk of structural recurrence. However, maintaining TSH levels at $0.1-0.5 \mathrm{mU} / \mathrm{L}$ is recommended for low-risk patients with biochemical evidence but no structural evidence of disease. Patients who remain disease free for several years can maintain TSH levels within the reference range.

The 2015 ATA guidelines (Haugen et al. 2016) recommend deciding postoperative management during the early postoperative period (within 2 years of initial treatment) based on the ATA initial risk estimates, which specify initial target TSH levels as $0.1-0.5 \mathrm{mU} / \mathrm{L}$ for ATA intermediate-risk patients and $0.5-2.0 \mathrm{mU} / \mathrm{L}$ for ATA lowrisk patients, assuming patients who have undergone thyroid lobectomy while monitoring for structural recurrence by neck ultrasonography and measuring serum Tg/anti-Tg antibody and TSH. However, a retrospective multivariate analysis of 1047 PTC patients with a median follow-up duration of 107 months (range: 13-216 months) demonstrated that structural recurrence only occurred in 42 patients (4.0\%); additionally, TSH levels at 1 year after initial surgery (HR 1.15 (95\% CI 1.03-1.28), $P=0.013$ ) were an independent risk factor for structural recurrence and significantly associated with DFS $(P=0.012)$ (Park et al. 2018a). The cut-off of TSH levels affecting structural recurrence was $1.85 \mathrm{mU} / \mathrm{L}$, calculated by receiver-operating curve (Park et al. 2018a). Interestingly, this study found that ATA risk category (low- or intermediate-risk) was not associated with structural recurrence by either univariate or multivariate analysis. Target TSH values of $<1.85 \mathrm{mU} / \mathrm{L}$ during the early postoperative period are within the target TSH levels $(0.5-2.0 \mathrm{mU} / \mathrm{L})$ recommended for ATA low-risk patients after thyroid lobectomy, but higher than that (0.1-0.5 mU/L) recommended for ATA intermediate-risk patients. Although further studies are needed to confirm target TSH levels after thyroid lobectomy, these results suggest that ATA intermediate-risk patients, like ATA lowrisk patients, can be monitored using TSH levels at a lownormal range during the early postoperative period prior to evaluating initial therapy responses. https://erc.bioscientifica.com https://doi.org/10.1530/ERC-19-0085 (c) 2019 Society for Endocrinology Published by Bioscientifica Ltd. Printed in Great Britain 


\section{Long-term follow-up strategies for DTC patients undergoing thyroid lobectomy}

The ATA initial risk stratification systems can guide initial treatment, including the extent of surgery, the need for RAI remnant ablation and TSH suppression, and the intensity and type of early follow-up studies. However, these systems only provide static representations of risk based on data available at initial treatment, and do not include data obtained during follow-up to allow evaluation of the response to initial therapy. Recently, a DRS system based on the response to initial therapy (excellent, indeterminate, biochemical incomplete or structural incomplete) has been proposed to more accurately predict long-term outcomes and to guide follow-up strategies by reclassifying initial risk estimates only based on histopathologic findings. Each responseto-therapy category of DRS is determined by detailed definitions according to the initial treatments, using data obtained during the first 2 years after initial treatment (Table 3). The DRS system has mainly been validated in patients treated with total thyroidectomy and RAI remnant ablation, demonstrating that the capability of the DRS system (PVE, 62-84\%) to predict long-term structural recurrence has more statistical power than the ATA initial risk stratification system (PVE, 25-34\%) (Tuttle et al. 2010, Castagna et al. 2011, Haugen et al. 2016).

While the DRS is focused on patients undergoing total thyroidectomy and subsequent RAI remnant ablation, it can also be applied to patients with DTC undergoing thyroid lobectomy or total thyroidectomy without RAI remnant ablation, by using modified definitions of the response-to-therapy categories (Table 3). Recent studies showed that the DRS system was effective for modifying the initial risk estimates of structural recurrence/persistence and provided valuable information for predicting structural recurrence even in thyroid lobectomy patients (Vaisman et al. 2013, Momesso et al. 2014).

Retrospective studies compared the capability of the DRS in predicting long-term structural recurrence with that of the ATA initial risk estimates, with regard to their PVEs. One study of 619 PTC patients treated with thyroid lobectomy revealed that the PVE of the DRS system (32.4\%) was higher than that of the ATA risk estimates (29.4\%), but lower than what was described for patients treated with total thyroidectomy with RAI remnant ablation (Cho et al. 2018).

Table 3 Definition of each response to initial therapy in dynamic risk stratification system using data from within 2 years or at any time after surgery.

\begin{tabular}{|c|c|c|c|}
\hline \multirow[b]{2}{*}{$\begin{array}{l}\text { Response to therapy } \\
\text { category }\end{array}$} & \multicolumn{3}{|c|}{ Definitions } \\
\hline & $\begin{array}{l}\text { Total thyroidectomy with RAI remnant } \\
\text { ablation }\end{array}$ & $\begin{array}{l}\text { Total thyroidectomy without RAI } \\
\text { remnant ablation }\end{array}$ & Thyroid lobectomy alone \\
\hline \multirow[t]{2}{*}{ Excellent } & $\begin{array}{l}\text { Non-stimulated } \mathrm{Tg}<0.2 \mathrm{ng} / \mathrm{mL} \\
\text { or stimulated } \mathrm{Tg}<1.0 \mathrm{ng} / \mathrm{mL}\end{array}$ & $\begin{array}{l}\text { Non-stimulated } \mathrm{Tg}<0.2 \mathrm{ng} / \mathrm{mL} \\
\text { or stimulated } \mathrm{Tg}<2.0 \mathrm{ng} / \mathrm{mL}\end{array}$ & $\begin{array}{l}\text { Non-stimulated } \mathrm{Tg}<30 \mathrm{ng} / \mathrm{mL} \\
\text { and undetectable anti-TgAb } \\
\text { levels }\end{array}$ \\
\hline & $\begin{array}{l}\text { and undetectable anti-TgAb levels } \\
\text { and negative imaging }\end{array}$ & $\begin{array}{l}\text { and undetectable anti-TgAb levels } \\
\text { and negative imaging }\end{array}$ & and negative imaging \\
\hline \multirow[t]{4}{*}{ Indeterminate } & $\begin{array}{l}\text { Non-stimulated Tg } 0.2-1 \mathrm{ng} / \mathrm{mL} \\
\text { or stimulated } \operatorname{Tg} 1-10 \mathrm{ng} / \mathrm{mL}\end{array}$ & $\begin{array}{l}\text { Non-stimulated Tg } 0.2-5.0 \mathrm{ng} / \mathrm{mL} \\
\text { or stimulated } \operatorname{Tg} 2-10 \mathrm{ng} / \mathrm{mL}\end{array}$ & \\
\hline & $\begin{array}{l}\text { or stable or declining anti-TgAb } \\
\text { levels in the absence of } \\
\text { structural or functional disease }\end{array}$ & $\begin{array}{l}\text { or stable or declining anti-TgAb } \\
\text { levels in the absence of } \\
\text { structural or functional disease }\end{array}$ & $\begin{array}{l}\text { Stable or declining anti-TgAb } \\
\text { levels in the absence of } \\
\text { structural or functional disease }\end{array}$ \\
\hline & $\begin{array}{l}\text { or nonspecific findings in imaging } \\
\text { studies }\end{array}$ & $\begin{array}{l}\text { or nonspecific findings in imaging } \\
\text { studies }\end{array}$ & $\begin{array}{l}\text { or nonspecific findings in imaging } \\
\text { studies }\end{array}$ \\
\hline & $\begin{array}{l}\text { or faint uptake in thyroid bed on } \\
\text { RAl scanning }\end{array}$ & $\begin{array}{l}\text { or faint uptake in thyroid bed on } \\
\text { RAl scanning }\end{array}$ & \\
\hline \multirow[t]{3}{*}{$\begin{array}{l}\text { Biochemical } \\
\text { incomplete }\end{array}$} & $\begin{array}{l}\text { Non-stimulated (suppressed) Tg } \\
>1 \mathrm{ng} / \mathrm{mL}\end{array}$ & $\begin{array}{l}\text { Non-stimulated (suppressed) Tg } \\
>5 \mathrm{ng} / \mathrm{mL}\end{array}$ & Non-stimulated $\mathrm{Tg}>30 \mathrm{ng} / \mathrm{mL}$ \\
\hline & or stimulated $\mathrm{Tg}>10 \mathrm{ng} / \mathrm{mL}$ & or stimulated $\mathrm{Tg}>10 \mathrm{ng} / \mathrm{mL}$ & $\begin{array}{l}\text { or increasing Tg values with } \\
\text { similar TSH levels }\end{array}$ \\
\hline & $\begin{array}{l}\text { or rising anti-TgAb levels and } \\
\text { negative imaging }\end{array}$ & $\begin{array}{l}\text { or rising anti-TgAb levels and } \\
\text { negative imaging }\end{array}$ & $\begin{array}{l}\text { or rising anti-TgAb levels and } \\
\text { negative imaging }\end{array}$ \\
\hline \multirow[t]{2}{*}{ Structural incomplete } & $\begin{array}{l}\text { Structural or functional evidence } \\
\text { of disease }\end{array}$ & $\begin{array}{l}\text { Structural or functional evidence } \\
\text { of disease }\end{array}$ & $\begin{array}{l}\text { Structural or functional evidence } \\
\text { of disease }\end{array}$ \\
\hline & $\begin{array}{l}\text { regardless of Tg or anti-TgAb } \\
\text { levels }\end{array}$ & $\begin{array}{l}\text { regardless of Tg or anti-TgAb } \\
\text { levels }\end{array}$ & regardless of Tg or anti-TgAb \\
\hline
\end{tabular}

RAl, radioactive iodine; $T g$, thyroglobulin; $T g A b, T g$ antibody.

https://erc bioscientifica com https://doi.org/10.1530/ERC-19-0085 (c) 2019 Society for Endocrinology Published by Bioscientifica Ltd. Printed in Great Britain 
Another study analysed 357 DTC patients receiving thyroid lobectomy or total thyroidectomy without RAI remnant ablation, finding that the PVE of the DRS system (12.2\%) was much higher than that of the ATA risk estimates $(0.74 \%)$, and the risk of recurrent/persistent disease was significantly greater in the biochemicalincomplete response $(\mathrm{HR}=20.8$ (95\% CI 4.0-107.1), $P<0.001)$ and structural-incomplete response group $(\mathrm{HR}=243.3$ (95\% CI 46.5-1272.1), $P<0.001)$ than in the excellent response group (Park et al. 2017).

When considering these results, it makes sense that long-term follow-up strategies, including monitoring target TSH levels, are guided by the DRS based on the response to initial therapy rather than ATA initial risk estimates. Follow-up after thyroid lobectomy relies on neck ultrasonography with non-stimulated serum $\mathrm{Tg} / \mathrm{anti}-\mathrm{Tg}$ antibodies at 6-12-month intervals after initial therapy. If these follow-ups are unremarkable, non-stimulated serum $\mathrm{Tg} /$ anti-Tg antibodies can be obtained annually and neck ultrasonography performed at 3-5-year intervals. The TSH target is recommended to be maintained between $0.5-2.0 \mathrm{mU} / \mathrm{L}$ for patients with an excellent initial therapy response, $0.5-1.0 \mathrm{mU} / \mathrm{L}$ for patients with an indeterminate or biochemically incomplete response and about $0.1 \mathrm{mU} / \mathrm{L}$ for patients with a structurally incomplete response.

\section{Declaration of interest}

The authors declare that there is no conflict of interest that could be perceived as prejudicing the impartiality of this review.

\section{Funding}

This work did not receive any specific grant from any funding agency in the public, commercial, or not-for-profit sector.

\section{References}

American Thyroid Association (ATA) Guidelines Taskforce on Thyroid Nodules and Differentiated Thyroid Cancer, Cooper DS, Doherty GM, Haugen BR, Kloos RT, Lee SL, Mandel SJ, Mazzaferri EL, McIver B, Pacini F, et al. 2009 Revised American Thyroid Association management guidelines for patients with thyroid nodules and differentiated thyroid cancer. Thyroid 19 1167-1214. (https://doi. org/10.1089/thy.2009.0110)

Asioli S, Erickson LA, Righi A \& Lloyd RV 2013 Papillary thyroid carcinoma with hobnail features: histopathologic criteria to predict aggressive behaviour. Human Pathology 44 320-328. (https://doi. org/10.1016/j.humpath.2012.06.003)

Cao J, Hu JL, Chen C, Wang QL, Fang XH, Zhang Y \& Ge MH 2016 Vascular invasion is an independent prognostic factor for distant recurrence-free survival in papillary thyroid carcinoma: a matchedcase comparative study. Journal of Clinical Pathology 69 872-877. (https://doi.org/10.1136/jclinpath-2015-203547)
Castagna MG, Maino F, Cipri C, Belardini V, Theodoropoulou A, Cevenini G \& Pacini F 2011 Delayed risk stratification, to include the response to initial treatment (surgery and radioiodine ablation), has better outcome predictivity in differentiated thyroid cancer patients. European Journal of Endocrinology 165 441-446. (https://doi. org/10.1530/EJE-11-0466)

Chen Y, Sadow PM, Suh H, Lee KE, Choi JY, Suh YJ, Wang TS \& Lubitz CC 2016 BRAF(V600E) is correlated with recurrence of papillary thyroid microcarcinoma: a systematic review, multi-institutional primary data analysis, and meta-analysis. Thyroid 26 248-255. (https://doi.org/10.1089/thy.2015.0391)

Cho JW, Lee YM, Lee YH, Hong SJ \& Yoon JH 2018 Dynamic risk stratification system in post-lobectomy low-risk and intermediaterisk papillary thyroid carcinoma patients. Clinical Endocrinology 89 100-109. (https://doi.org/10.1111/cen.13721)

Collini P, Sampietro G \& Pilotti S 2004 Extensive vascular invasion is a marker of risk of relapse in encapsulated non-Hurthle cell follicular carcinoma of the thyroid gland: a clinicopathological study of 18 consecutive cases from a single institution with a 11-year median follow-up. Histopathology 44 35-39.

Durante C, Montesano T, Attard M, Torlontano M, Monzani F, Costante G, Meringolo D, Ferdeghini M, Tumino S, Lamartina L, et al. 2012 Long term surveillance of papillary thyroid cancer patients who do not undergo postoperative radioiodine remnant ablation: is there a role for serum thyroglobulin measurement? Journal of Clinical Endocrinology and Metabolism 97 2748-2753. (https://doi.org/10.1210/jc.2012-1123)

Elisei R, Viola D, Torregrossa L, Giannini R, Romei C, Ugolini C, Molinaro E, Agate L, Biagini A, Lupi C, et al. 2012 The BRAF(V600E) mutation is an independent, poor prognostic factor for the outcome of patients with low-risk intrathyroid papillary thyroid carcinoma: single-institution results from a large cohort study. Journal of Clinical Endocrinology and Metabolism 97 4390-4398. (https://doi. org/10.1210/jc.2012-1775)

Fernandez IJ, Piccin O, Sciascia S, Cavicchi O, Repaci A, Vicennati V \& Fiorentino M 2013 Clinical significance of BRAF mutation in thyroid papillary cancer. Otolaryngology: Head and Neck Surgery 148 919-925. (https://doi.org/10.1177/0194599813481942)

Goldstein NS, Czako P \& Neill JS 2000 Metastatic minimally invasive (encapsulated) follicular and hurthle cell thyroid carcinoma: a study of 34 patients. Modern Pathology 13 123-130. (https://doi. org/10.1038/modpathol.3880023)

Haddad RI, Lydiatt WM, Bischoff L, Busaidy NL, Byrd D, Callender G, Dickson P, Duh Q-Y, Ehya H, Haymart M, et al. 2016 NCCN Clinical Practice Guidelines in Oncology (NCCN Guidelines) for thyroid carcinoma, version 1.2016. Fort Washington, PA, USA: National Comprehensive Cancer Network, Inc. (available at: https://www. nccn.org/professionals/physician_gls/f_guidelines.asp\#thyroid)

Haugen BR, Alexander EK, Bible KC, Doherty GM, Mandel SJ, Nikiforov YE, Pacini F, Randolph GW, Sawka AM, Schlumberger, et al. 20162015 American Thyroid Association management guidelines for adult patients with thyroid nodules and differentiated thyroid cancer: the American Thyroid Association Guidelines Task Force on Thyroid Nodules and Differentiated Thyroid Cancer. Thyroid 26 1-133. (https://doi.org/10.1089/thy.2015.0020)

Huang CC, Hsueh C, Liu FH, Chao TC \& Lin JD 2011 Diagnostic and therapeutic strategies for minimally and widely invasive follicular thyroid carcinomas. Surgical Oncology 20 1-6 (https://doi. org/10.1016/j.suronc.2009.06.006)

Ito Y, Kudo T, Kihara M, Takamura Y, Kobayashi K, Miya A \& Miyauchi A 2012 Prognosis of low-risk papillary thyroid carcinoma patients: its relationship with the size of primary tumours. Endocrine Journal 59 119-125.

Kandil E, Noureldine SI, Abbas A \& Tufano RP 2013 The impact of surgical volume on patient outcomes following thyroid surgery. (c) 2019 Society for Endocrinology Published by Bioscientifica Ltd. Printed in Great Britain 
Surgery 154 1346-1352; discussion 1352. (https://doi.org/10.1016/j. surg.2013.04.068)

Kazaure HS, Roman SA \& Sosa JA 2012 Aggressive variants of papillary thyroid cancer: incidence, characteristics and predictors of survival among 43,738 patients. Annals of Surgical Oncology 19 1874-1880. (https://doi.org/10.1245/s10434-011-2129-x)

Kim TY, Kim WB, Rhee YS, Song JY, Kim JM, Gong G, Lee S, Kim SY, Kim SC, Hong SJ, et al. 2006 The BRAF mutation is useful for prediction of clinical recurrence in low-risk patients with conventional papillary thyroid carcinoma. Clinical Endocrinology 65 364-368. (https://doi.org/10.1111/j.1365-2265.2006.02605.x)

Lang W, Choritz H \& Hundeshagen H 1986 Risk factors in follicular thyroid carcinomas. A retrospective follow-up study covering a 14-year period with emphasis on morphological findings. American Journal of Surgical Pathology 10 246-255 (https://doi. org/10.1097/00000478-198604000-00003)

Leboulleux S, Rubino C, Baudin E, Caillou B, Hartl DM, Bidart JM, Travagli JP \& Schlumberger M 2005 Prognostic factors for persistent or recurrent disease of papillary thyroid carcinoma with neck lymph node metastases and/or tumor extension beyond the thyroid capsule at initial diagnosis. Journal of Clinical Endocrinology and Metabolism 90 5723-5729. (https://doi.org/10.1210/jc.2005-0285)

Lee J, Song Y \& Soh EY 2014 Prognostic significance of the number of metastatic lymph nodes to stratify the risk of recurrence. World Journal of Surgery 38 858-862. (https://doi.org/10.1007/s00268-013-2345-6)

Lee YM, Sung TY, Kim WB, Chung KW, Yoon JH \& Hong SJ 2016 Risk factors for recurrence in patients with papillary thyroid carcinoma undergoing modifiedradical neck dissection. British Journal of Surgery 103 1020-1025. (https://doi.org/10.1002/bjs.10144)

Lee YM, Lee YH, Song DE, Kim WB, Sung TY, Yoon JH, Chung KW \& Hong SJ 2017 Prognostic impact of further treatments on distant metastasis in patients With MinimallyInvasive follicular thyroid carcinoma: verification using inverse probability of TreatmentWeighting. World Journal of Surgery 41 138-145. (https:// doi.org/10.1007/s00268-016-3608-9)

Lee YM, Cho JW, Hong SJ \& Yoon JH 2018 Dynamic risk stratification in papillary thyroid carcinoma measuring 1 to $4 \mathrm{~cm}$. Journal of Surgical Oncology 118 636-643. (https://doi.org/10.1002/jso.25182)

Lee YM, Park JH, Cho JW, Hong SJ \& Yoon JH 2019 The definition of lymph node micrometastases in pathologic N1a papillary thyroid carcinoma should be revised. Surgery 165 652-656. (https://doi. org/10.1016/j.surg.2018.09.015)

Lo CY, Chan WF, Lam KY \& Wan KY 2005 Follicular thyroid carcinoma: the role of histology and staging systems in predicting survival. Annals of Surgery 242 708-715. (https://doi.org/10.1097/01. sla.0000186421.30982.d2)

Lombardi CP, Bellantone R, De Crea C, Paladino NC, Fadda G, Salvatori M \& Raffaelli M 2010 Papillary thyroid microcarcinoma: extrathyroidal extension, lymph node metastases, and risk factors for recurrence in a high prevalence of goiter area. World Journal of Surgery 34 1214-1221. (https://doi.org/10.1007/s00268-0090375-x)

Lubitz CC, Economopoulos KP, Pawlak AC, Lynch K, Dias-Santagata D, Faquin WC \& Sadow PM 2014 Hobnail variant of papillary thyroid carcinoma: an institutional case series and molecular profile. Thyroid 24 958-965. (https://doi.org/10.1089/thy.2013.0573)

Matsuzu K, Sugino K, Masudo K, Nagahama M, Kitagawa W, Shibuya H, Ohkuwa K, Uruno T, Suzuki A, Magoshi S, et al. 2014 Thyroid lobectomy for papillary thyroid cancer: long-term follow-up study of 1,088 cases. World Journal of Surgery 38 68-79. (https://doi. org/10.1007/s00268-013-2224-1)

Michels JJ, Jacques M, Henry-Amar M \& Bardet S 2007 Prevalence and prognostic significance of tall cell variant of papillary thyroid carcinoma. Human Pathology 38 212-219. (https://doi.org/10.1016/j. humpath.2006.08.001)
Momesso DP \& Tuttle RM 2014 Update on differentiated thyroid cancer staging. Endocrinology and Metabolism Clinics of North America 43 401-421. (https://doi.org/10.1016/j.ecl.2014.02.010)

Morris LG, Shaha AR, Tuttle RM, Sikora AG \& Ganly I 2010 Tall-cell variant of papillary thyroid carcinoma: a matched-pair analysis of survival. Thyroid 20 153-158. (https://doi.org/10.1089/ thy.2009.0352)

Nath MC \& Erickson LA 2018 Aggressive variants of papillary thyroid carcinoma: hobmail, tall cell, columnar, and solid. Advances in Anatomic Pathology 25 172-179. (https://doi.org/10.1097/ PAP.0000000000000184)

Nixon IJ, Ganly I, Patel SG, Palmer FL, Whitcher MM, Tuttle RM, Shaha A \& Shah JP 2012 Thyroid lobectomy for treatment of well differentiated intrathyroid malignancy. Surgery 151 571-579. (https://doi.org/10.1016/j.surg.2011.08.016)

O'Neill CJ, Vaughan L, Learoyd DL, Sidhu SB, Delbridge LW \& Sywak MS 2011 Management of follicular thyroid carcinoma should be individualised based on degree of capsular and vascular invasion. European Journal of Surgical Oncology 37 181-185. (https://doi. org/10.1016/j.ejso.2010.11.005)

Park S, Kim WG, Song E, Oh HS, Kim M, Kwon H, Jeon MJ, Kim TY, Shong YK \& Kim WB 2017 Dynamic risk stratification for predicting recurrence in patients with differentiated thyroid cancer treated Without radioactive iodine remnant ablation therapy. Thyroid $\mathbf{2 7}$ 524-530. (https://doi.org/10.1089/thy.2016.0477)

Park JH, Lee YM, Lee YH, Hong SJ \& Yoon JH 2018a The prognostic value of serum thyroid-stimulating hormone level post-lobectomy in low- and intermediate-risk papillary thyroid carcinoma. Journal of Surgical Oncology 118 390-396. (https://doi.org/10.1002/jso.25164)

Park SY, Kim HI, Kim JH, Kim JS, Oh YL, Kim SW, Chung JH, Jang HW \& Kim TH $2018 b$ Prognostic significance of gross extrathyroidal extension invading only strap muscles in differentiated thyroid carcinoma. British Journal of Surgery 105 1155-1162. (https://doi. org/10.1002/bjs.10830)

Perros P, Boelaert K, Colley S, Evans C, Evans RM, Gerrard Ba G, Gilbert J, Harrison B, Johnson SJ, Giles TE, et al. 2014 Guidelines for the management of thyroid cancer. Clinical Endocrinology $\mathbf{8 1}$ (Supplement 1) 1-122. (https://doi.org/10.1111/cen.12515)

Radowsky JS, Howard RS, Burch HB \& Stojadinovic A 2014 Impact of degree of extrathyroidal extension of disease on papillary thyroid cancer outcome. Thyroid 24 241-244. (https://doi.org/10.1089/ thy.2012.0567)

Rajjoub SR, Yan H, Calcatera NA, Kuchta K, Wang CE, Lutfi W, MooYoung TA, Winchester DJ \& Prinz RA 2018 Thyroid lobectomy is not sufficient for T2 papillary thyroid cancers. Surgery 163 1134-1143. (https://doi.org/10.1016/j.surg.2017.12.026)

Randolph GW, Duh QY, Heller KS, LiVolsi VA, Mandel SJ, Steward DL, Tufano RP, Tuttle RM \& American Thyroid Association Surgical Affairs Committee's Taskforce on Thyroid Cancer Nodal Surgery 2012 The prognostic significance of nodal metastases from papillary thyroid carcinoma can be stratified based on the size and number of metastatic LNs, as well as the presence of extranodal extension. Thyroid 22 1144-1152. (https://doi.org/10.1089/thy.2012.0043)

Ricarte-Filho JC, Ryder M, Chitale DA, Rivera M, Heguy A, Ladanyi M, Janakiraman M, Solit D, Knauf JA, Tuttle RM, et al. 2009 Mutational profile of advanced primary and metastatic radioactive iodinerefractory thyroid cancers reveals distinct pathogenetic roles for BRAF, PIK3CA, and AKT1. Cancer Research 69 4885-4893. (https:// doi.org/10.1158/0008-5472.CAN-09-0727)

Roti E, degli Uberti EC, Bondanelli M \& Braverman LE 2008 Thyroid papillary microcarcinoma: a descriptive and meta-analysis study. European Journal of Endocrinology 159 659-673. (https://doi. org/10.1530/EJE-07-0896)

Song E, Jeon MJ, Oh HS, Han M, Lee YM, Kim TY, Chung KW, Kim WB, Shong YK, Song DE, et al. 2018 Do aggressive variants of papillary https://erc.bioscientifica.com https://doi.org/10.1530/ERC-19-0085 (c) 2019 Society for Endocrinology Published by Bioscientifica Ltd. Printed in Great Britain 
thyroid carcinoma have worse clinical outcome than classic papillary thyroid carcinoma? European Journal of Endocrinology 179 135-142. (https://doi.org/10.1530/EJE-17-0991)

Song E, Han M, Oh HS, Kim WW, Jeon MJ, Lee YM, Kim TY, Chung KW, Kim WB, Shong YK, et al. 2019 Lobectomy is feasible for $1-4 \mathrm{~cm}$ papillary thyroid carcinomas: a 10-year propensity score matchedpair analysis on recurrence. Thyroid 29 64-70. (https://doi. org/10.1089/thy.2018.0554)

Sosa JA, Bowman HM, Tielsch JM, Powe NR, Gordon TA \& Udelsman R 1998 The importance of surgeon experience for clinical and economic outcomes from thyroidectomy. Annals of Surgery 228 320-330 (https://doi.org/10.1097/00000658-199809000-00005)

Sugino K, Ito K, Nagahama M, Kitagawa W, Shibuya H, Ohkuwa K, Yano Y, Uruno T, Akaishi J, Kameyama K, et al. 2011 Prognosis and prognostic factors for distant metastases and tumor mortality in follicular thyroid carcinoma. Thyroid 21 751-757. (https://doi. org/10.1089/thy.2010.0353)

Tam S, Amit M, Boonsripitayanon M, Busaidy NL, Cabanillas ME, Waguespack SG, Gross ND, Grubbs EG, Williams MD, Lai SY, et al. 2018 Effect of tumor size and minimal extrathyroidal extension in patients with differentiated thyroid cancer. Thyroid 28 982-990. (https://doi.org/10.1089/thy.2017.0513)

Terry JHSt, John SA, Karkowski FJ, Suarez JR, Yassa NH, Platica CD \& Marti JR 1994 Tall cell papillary thyroid cancer: incidence and prognosis. American Journal of Surgery 168 459-461 (https://doi. org/10.1016/S0002-9610(05)80099-6)

Tufano RP, Teixeira GV, Bishop J, Carson KA \& Xing M 2012 BRAF mutation in papillary thyroid cancer and its value in tailoring initial treatment: a systematic review and meta-analysis. Medicine $\mathbf{9 1}$ 274-286. (https://doi.org/10.1097/MD.0b013e31826a9c71)

Tuttle RM, Tala H, Shah J, Leboeuf R, Ghossein R, Gonen M, Brokhin M, Omry G, Fagin JA \& Shaha A 2010 Estimating risk of recurrence in differentiated thyroid cancer after total thyroidectomy and radioactive iodine remnant ablation: using response to therapy variables to modify the initial risk estimates predicted by the new American Thyroid Association staging system. Thyroid 20 1341-1349. (https://doi.org/10.1089/thy.2010.0178)

Vaisman F, Shaha A, Fish S \& Michael Tuttle R 2011 Initial therapy with either thyroid lobectomy or total thyroidectomy without radioactive iodine remnant ablation is associated with very low rates of structural disease recurrence in properly selected patients with differentiated thyroid cancer. Clinical Endocrinology 75 112-119. (https://doi.org/10.1111/j.1365-2265.2011.04002.x)
Vaisman F, Momesso D, Bulzico DA, Pessoa CH, da Cruz MD, Dias F, Corbo R, Vaisman M \& Tuttle RM 2013 Thyroid lobectomy is associated with excellent clinical outcomes in properly selected differentiated thyroid cancer patients with primary tumors greater than $1 \mathrm{~cm}$. Journal of Thyroid Research 2013 398194. (https://doi. org/10.1155/2013/398194)

Voutilainen PE, Siironen P, Franssila KO, Sivula A, Haapiainen RK \& Haglund CH 2003 AMES, MACIS and TNM prognostic classifications in papillary thyroid carcinoma. Anticancer Research 23 4283-4288.

Wang F, Yu X, Shen X, Zhu G, Huang Y, Liu R, Viola D, Elisei R, Puxeddu E, Fugazzola L, et al. 2017 The prognostic value of tumor multifocality in clinical outcomes of papillary thyroid cancer. Journal of Clinical Endocrinology and Metabolism 102 3241-3250. (https://doi. org/10.1210/jc.2017-00277)

Wreesmann VB, Nixon IJ, Rivera M, Katabi N, Palmer F, Ganly I, Shaha AR, Tuttle RM, Shah JP, Patel SG, et al. 2015 Prognostic value of vascular invasion in well-differentiated papillary thyroid carcinoma. Thyroid $\mathbf{2 5}$ 503-508. (https://doi.org/10.1089/thy.2015.0052)

Xing M, Westra WH, Tufano RP, Cohen Y, Rosenbaum E, Rhoden KJ, Carson KA, Vasko V, Larin A, Tallini G, et al. 2005 BRAF mutation predicts a poorer clinical prognosis for papillary thyroid cancer. Journal of Clinical Endocrinology and Metabolism 90 6373-6379. (https://doi.org/10.1210/jc.2005-0987)

Xing M, Alzahrani AS, Carson KA, Viola D, Elisei R, Bendlova B, Yip L, Mian C, Vianello F, Tuttle RM, et al. 2013 Association between BRAF V600E mutation and mortality in patients with papillary thyroid cancer. JAMA 309 1493-1501. (https://doi.org/10.1001/ jama.2013.3190)

Xing M, Liu R, Liu X, Murugan AK, Zhu G, Zeiger MA, Pai S \& Bishop J 2014 BRAF V600E and tert promoter mutations cooperatively identify the most aggressive papillary thyroid cancer With highest recurrence. Journal of Clinical Oncology 32 2718-2726. (https://doi. org/10.1200/JCO.2014.55.5094)

Xing M, Alzahrani AS, Carson KA, Shong YK, Kim TY, Viola D, Elisei R, Bendlová B, Yip L, Mian C, et al. 2015 Association between BRAF V600E mutation and recurrence of papillary thyroid cancer. Journal of Clinical Oncology 33 42-50. (https://doi.org/10.1200/ JCO.2014.56.8253)

Yildirim E 2005 A model for predicting outcomes in patients with differentiated thyroid cancer and model performance in comparison with other classification systems. Journal of the American College of Surgeons 200 378-392. (https://doi.org/10.1016/j. jamcollsurg.2004.10.031)

Received in final form 12 April 2019

Accepted 24 April 2019

Accepted Preprint published online 24 April 2019 (c) 2019 Society for Endocrinology Published by Bioscientifica Ltd. Printed in Great Britain 